\title{
Assessing the bioadhesivity of Acconon MC 8-2 EP/NF for gastroretention of floating microsponges of loratadine and achieving controlled drug delivery
}

\author{
Sonam Singh ${ }^{1}$, Kamla Pathak ${ }^{2 *}$ \\ ${ }^{1}$ Department of Pharmaceutics, Rajiv Academy for Pharmacy, Mathura, 281001, India \\ ${ }^{2}$ Department of Pharmaceutics, Pharmacy College Saifai, Uttar Pradesh University of Medical Sciences, Saifai, Etawah, 206130, \\ India \\ Received: Jul 15, 2016, Revised: Jul 24, 2016, Accepted: Aug 1, 2016
}

\begin{abstract}
The aim of the present work was to assess the feasibility of Acconon MC8-2 EP/NF as a bioadhesive material for developing controlled release gastroretentive microsponges of loratadine. Modified emulsion-solvent diffusion method was employed for the preparation of microsponges (F1-F9) based on $3^{2}$ factorial design. The amount of ethyl cellulose (EC) and polyvinyl alcohol (PVA) were selected as independent variables while particle size, entrapment efficiency and $\% \mathrm{CDR}$ were designated as dependent variables. The formulation (F1) with least particle size of $54 \pm 2.37 \mu \mathrm{m}$, entrapment efficiency of $65.98 \pm 2.21 \%$ and CDR of $88.15 \pm 1.59 \%$ at $8 \mathrm{~h}$ that followed zero order release kinetics was selected as optimized formulation. F1 was re-fabricated as bioadhesive microsponges (BF1) using Acconon MC 8-2 and assessed. The particle size of BFlincreased to $84 \pm 2.29 \mu \mathrm{m}$ whereas the entrapment efficiency lowered to $55.19 \pm 1.36 \%$ in comparison to $\mathrm{F} 1$. However, the $\mathrm{CDR}_{8 \mathrm{~h}}$ from $\mathrm{BF} 1(81.65 \pm 3.37 \%)$ was comparable to $\mathrm{F} 1$. Dynamic in vitro bioadhesion test confirmed the bioadhesive property of BF1. Ex vivo permeation across gastric mucin depicted $52.87 \% \mathrm{CDP}_{8 \mathrm{~h}}$ that followed zero order kinetics $\left(\mathrm{r}^{2}=\right.$ 0.9885). Scanning electron microscopy revealed spherical and highly porous surface. The FTIR studies revealed no chemical interaction between drug and excipients. Hence, the study affirmed the bioadhesive characteristics of Acconon MC 8-2 EP/NF for development of controlled release biaodhesive floating microsponges of loratadine.
\end{abstract}

Keywords: Acconon MC 8-2 EP/NF, bioadhesivity, loratadine, gastroretentive microsponges Pharm Biomed Res 2016; 2(2): 58-74～DOI: 10.18869/acadpub.pbr.2.2.9

\section{Introduction}

Loratadine, a BCS class II drug is an oral $\mathrm{H} 1$ antihistaminic agent which exhibits poor water solubility and consequently poor dissolution. Loratadine is absorbed in the proximal part of the gastrointestinal tract (GIT); is stable in acidic $\mathrm{pH}$, has a narrow therapeutic absorption window in the GIT and the presence of food enhances its bioavailability (1). The drug is available as tablets, oral suspension, syrup and quickdissolving tablets. All these dosage forms are challenged by hepatic first pass metabolism that may be minimized by developing modulated drug delivery systems.

The retention of oral dosage forms in the upper GIT is a viable option that by virtue of 
its ability to prolong contact time of dosage form with GI mucosa leads to higher bioavailability and hence therapeutic efficacy (2). Research inputs on gastroretentive systems of loratadine can be found in literature as floating tablets (3-5). Primarily these systems rely on sufficient swelling of the tablet to retard its expulsion from gastric cavity that present the potential hazard of permanent retention in the stomach and could be life-threatening upon multiple administrations (6). In contrast, multiple unit particulate dosage forms present the advantage of uniform passage through the GIT to avoid the vagaries of gastric emptying and provide an adjustable release, thereby, reducing the inter-subject variability in absorption and risk of local irritation. The multiparticulate gastroretentive dosage forms explored include oil entrapped floating microbeads (7) but are amenable to oil leakage on long term storage. The floating ability of microsponges devoid of lag time has been proven by our research group (8). Thus microsponges inclusive of their intrinsic advantages were selected as the novel gastroretentive floating drug delivery system for loratadine.

Although significant advances have been made in both floating and bioadhesive systems, there are still many challenges. First, the floating systems are unable to completely release the drug at the intended site. Second, gastric emptying may reduce the buoyancy of the floating systems in the stomach. Third, the turnover of the gastric mucosa and gastric emptying reduces the adhesive force of bioadhesive systems. A dual working system has the potential to overcome the drawbacks associated with bioadhesive and floating systems individually and would have a significant effect on improving the therapeutic outcomes (9). Here, the dosage form will float when gastric fluid is sufficiently present in stomach and when it empties buoyancy will be impeded and at that time bioadhesion will facilitate gastroretention. Thus, the aim of the present work was to formulate loratadine microsponges using bioadhesive- floating dual approach for gastroretention and enhance bioavailability.

\section{Materials and methods}

\section{Materials}

Loratadine was kind gift sample from Arti Pharmaceuticals, Surat, India. EC was procured from Ray Chemicals (P) Ltd., Bangalore, India, PVA from Himedia, New Delhi, India and dichloromethane was purchased from S.D. Fine Chemicals Ltd., Mumbai, India. Acconon MC 8-2 EP/NF was procured from ABITEC Corporation, Janesville, Wisconsin, USA.

\section{In vitro adsorption}

Excess amount of loratadine $(10 \mathrm{mg})$ was dispersed in $50 \mathrm{~mL}$ of double distilled water containing 10 fold weight of ethyl cellulose. The dispersion was stirred at $100 \mathrm{rpm}$ and $30 \pm 2^{\circ} \mathrm{C}$ for $8 \mathrm{~h}$. Samples were withdrawn at regular intervals of an hour, filtered, diluted appropriately and assayed spectrophotometrically (Shimadzu, Pharmaspec 1700, Tokyo, Japan) at $276 \mathrm{~nm}$. A graph was plotted between the $\%$ drug adsorbed versus time. Paired student t-test was applied to determine the optimum stirring time. 
Bioadhesive floating microsponges of loratadine 
The dependent variables were the particle size, entrapment efficiency and $\% \mathrm{CDR}_{8 \mathrm{~h}}$. A total of nine formulations (F1-F9) were prepared and assessed individually for the responses.

\section{Evaluation}

Yield and particle size

The yield of the microsponges was determined using following equation:

Yield $(\%)=$
$\frac{\text { Practical weight of microsponges }}{\text { Theoretical weight of polymer+drug }} X 100$

The particle size of microsponges was determined by optical microscopy. The sample was mounted on a slide and placed on the mechanical stage. Each determination was carried out on a minimum of 300 particles.

\section{Entrapment efficiency}

Accurately weighed amount of microsponges were crushed and $10 \mathrm{mg}$ of powder was dispersed in $5 \mathrm{~mL}$ of $0.1 \mathrm{~N} \mathrm{HCl}$ and heated for $10 \mathrm{~min}$ at $60 \pm 5^{\circ} \mathrm{C}$ followed by vortexing and filtration. The filtrate was diluted appropriately with phosphate buffer, $\mathrm{pH} 4.5$ and analyzed spectrophotometrically. The entrapment efficiency was calculated by eq 2 :

\section{Entrapment efficiency $(\%)=$ Practically entrapped drug amount Total amount of drugtexcipients

\section{In vitro drug release}

The release of drug from microsponges was determined by modified Rosette Rice apparatus (8). An accurately weighed amount of microsponges equivalent to 10 $\mathrm{mg}$ of drug was placed in modified beaker containing $70 \mathrm{~mL}$ of phosphate buffer, $\mathrm{pH}$ 4.5 containing $2 \% \mathrm{w} / \mathrm{v}$ tween 80 maintained at $37 \pm 0.5^{\circ} \mathrm{C}$ and $75 \mathrm{rpm}$. Samples of $2 \mathrm{~mL}$ were withdrawn at every hour till $8 \mathrm{~h}$ and replaced with fresh medium. The samples were diluted appropriately and assayed.

\section{Statistical analysis}

The effect of formulation variables on the response variables were statistically evaluated by Design-Expert ${ }^{\circledR}$ version 9.0.5.1 (Stat-Ease, Inc.). The optimized formulation was selected on the basis of minimum particle size, high entrapment efficiency, maximum in vitro cumulative drug release in $8 \mathrm{~h}$ and with good desirability factor.

Preparation and evaluation of bioadhesive microsponges

The optimized formulation (F1) was reformulated using $\mathrm{Ac}$ as polymeric surfactant with concentration $1 \% \mathrm{v} / \mathrm{v}$. The formulation requirements were similar to that of F1 except that the level of ethyl cellulose was changed to $80 \mathrm{mg}$ to get $\mathrm{BF}$. The bioadhesive microsponges prepared were assessed for the designated response and below detailed parameters.

\section{Dynamic in vitro bioadhesion}

The test was performed to evaluate the bioadhesive property of microsponges in reference to the uncoated microsponges. For the purpose, a lab fabricated device (Fig. 1) as described by our research team was used (11). Briefly, two stainless steel plates $(9.5 \times$ 


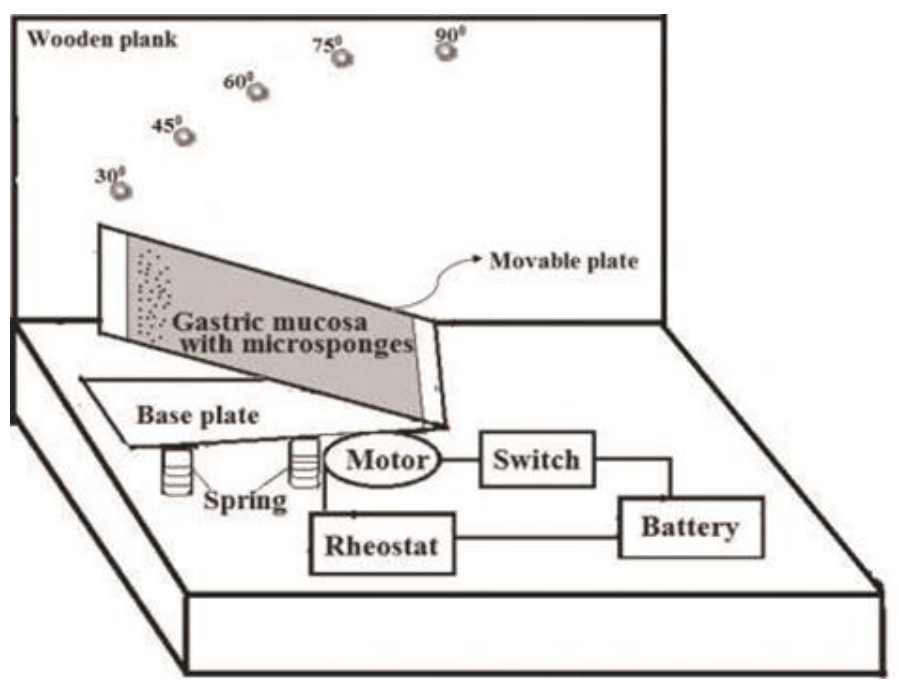

Figure 1 Diagrammatic representation of dynamic in vitro bioadhesion test assembly

$6.0 \mathrm{~cm}^{2}$ ) were hinged together: a manually movable plate (A) and base plate (B) supported on spring fixed on a wooden plank. At the hinged position of plates, a vibrating DC motor (D/V 5.9 RF 300C$114400)$ driven by a battery $(9 \mathrm{~V})$, with a current of $2.54 \mathrm{~mA}$, was placed. A rheostat was used in the circuit to provide a frequency of 3-5 cycles/min to simulate peristaltic movement in stomach. The base plank was attached to another vertical wooden plank. On the vertical plank, bolts were drilled at $0,30,45,60,75,90,120$ and $180^{\circ}$. The goat stomach mucosa $(8.5 \times$ $5.5 \mathrm{~cm}^{2}$ ) was mounted on the movable plate A that was made to move through variable angles for the experiment. Forty microsponges of BF1 were hydrated in phosphate buffer, $\mathrm{pH} 4.5$ for $30 \mathrm{~min}$ and placed over the mucosa, resting at $0^{0}$. Plate $\mathrm{A}$ was made to move at $30^{\circ}$ and allowed to vibrate for $3 \mathrm{~min}$. The movement of the microsponges was carefully observed and recorded. The plate was then moved to 45 ,
60,75 and $90^{\circ}$ and the experiment repeated. The dynamic in vitro bioadhesion test was also performed for $\mathrm{F} 1$.

\section{Ex-vivo permeation}

The ex vivo permeation of bioadhesive microsponges through gastric mucin was studied using modified vertical Franz diffusion. The freshly excised abomasum part of goat stomach was procured from the local slaughter house. Gastric mucin was scrapped off carefully by blunt end of spatula. The mucin sample was purified with repeated changes of distilled water and the centrifuged at $2000 \mathrm{rpm}$ for $10 \mathrm{~min}$. The obtained gelatinous mass (500 mg) was reconstituted with $10 \mathrm{~mL}$ of phosphate buffer, $\mathrm{pH} 4.5$ and mixed to produce gel. The reconstituted gastric mucin $(1.25 \mathrm{~mL})$ was placed over the dialysis membrane (MW 10-20 kDa) followed by another layer of dialysis membrane placed over it, so as that mucin was sandwiched between the two membranes. The assembly was mounted on the receptor compartment $\left(0.785 \mathrm{~cm}^{2}\right)$ of 
the diffusion cell. The receptor compartment was filled with $10 \mathrm{~mL}$ of phosphate buffer, $\mathrm{pH}$ 4.5. Bioadhesive microsponges (BF1) equivalent to $10 \mathrm{mg}$ of drug were placed in the donor compartment and hydrated with phosphate buffer, $\mathrm{pH}$ 4.5. The assembly was maintained at $37^{\circ} \mathrm{C}$ and $2 \mathrm{~mL}$ sample was withdrawn from receptor compartment at hourly intervals till $8 \mathrm{~h}$, replaced with equal volume of phosphate buffer and assayed spectrophotometrically at $275 \mathrm{~nm}$.

\section{Scanning electron microscopy}

The morphology and appearance of drug, F1 and BF1 formulations were examined by scanning electron microscope. The prepared microsponges were mounted on the aluminium stub and coated with pure gold by Sputter coater (Polaron-SC7640, England, UK) under vacuum. The coated samples were then examined using scanning electron microscope (Carl Zeiss Evo 40, Cambridge, UK) operating at 20 $\mathrm{kV}$. Images were taken at different magnifications.

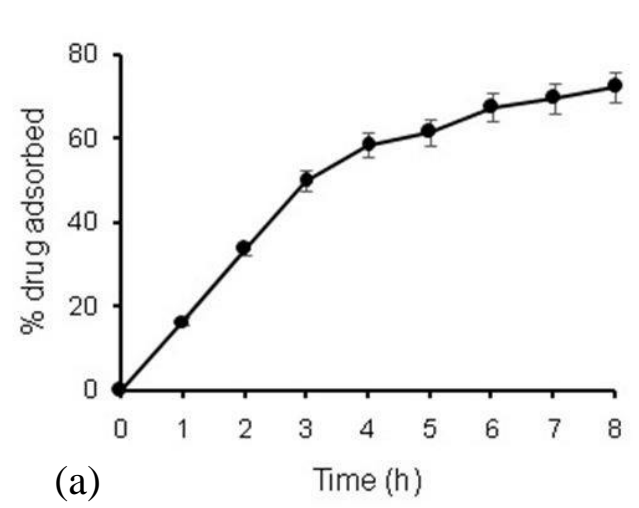

\section{Interaction assessment}

The drug-excipient interaction studies were carried out using Fourier Transform Infrared Spectrophotometer (Shimadzu, Japan). Infra red spectra of pure drug, physical mixture of drug and excipients, optimized formulation and bioadhesive formulation were recorded in the region 4000 to $500 \mathrm{~cm}^{-1}$.

\section{Results}

In vitro adsorption

The in vitro adsorption of loratadine on ethyl cellulose was found to be $72.33 \%$ in $8 \mathrm{~h}$. The in vitro adsorption profile (Fig. 2a) was biphasic in nature. EC showed rapid adsorption initially that slowed down after 4 $\mathrm{h}$ due to limited availability of adsorption sites and consequently an insignificant difference $(p>0.05)$ was recorded between 4 and $5 \mathrm{~h}$. Therefore, a stirring time of $4 \mathrm{~h}$ was selected for fabricating microsponges.

\section{Equilibrium solubility}

The solubility of loratadine $(0.0049 \mathrm{mg} / \mathrm{mL})$ was increased inconsiderably by 1.59 fold in

Fig. 2 (a) In vitro adsorption profile of loratadine on ethyl cellulose; (b) Bar chart representing equilibrium solubility of loratadine in the presence of various excipients 
the presence of EC (Fig. 2b). However, in the presence of both, EC and Ac the solubility of loratadine attained an intermediate value of 3.57 fold due to the counteracting effect of the hydrophobic microenvironment of EC.

\section{Loratadine microsponges}

The emulsion solvent diffusion method was modified with respect to the process variables such as stirrer type (magnetic stirrer), speed (400 rpm), temperature $\left(30 \pm 5^{\circ} \mathrm{C}\right)$, stirring time $(4 \mathrm{~h})$ and the volume of internal phase (using $5 \mathrm{~mL}$ instead of $20 \mathrm{~mL}$ ). Physically the microsponges were translucent spherical free flowing particles.

\section{Evaluation of microsponges}

\section{Yield}

The yield of microsponges varied between 42.33 and $90.23 \%$ (Table 2). The yield was affected both by amount of EC as well as by concentration of PVA. As the concentration of PVA was increased from 5 to $7.5 \% \mathrm{w} / \mathrm{v}$, the yield increased. Furthermore, for a given concentration of PVA, on increasing the level of EC, the yield increased. Thus F1 exhibited minimum yield $(42.33 \%)$ because it was fabricated using lower level(s) of both EC and PVA and maximum yield $(90.23 \%)$ was observed for F6 made with higher levels of EC and intermediate level of PVA. However, practical yield was less than the theoretical yield due to the loss of product due to the formation of some agglomerates and partial adherence of EC the container walls as a result of viscous nature of the slurry. A minor fraction of EC droplets aggregated and got precipitated as film around the magnetic bead or on the surface of aqueous phase affecting the yield.

\section{Particle size}

The average particle size of the formulations ranged from $54 \pm 2.37 \mu \mathrm{m}$ to $110 \pm 1.77 \mu \mathrm{m}$ (Table 2). On increasing the concentration of PVA from 5 to $7.5 \% \mathrm{w} / \mathrm{v}$, the emulsion droplets got stabilized. The largest particle size $(110 \pm 1.77 \mu \mathrm{m})$ was observed at high level of EC and PVA for F9 formulation while the least particle size $(54 \pm 2.37 \mu \mathrm{m})$ was noticed at low level of EC and PVA for F1.

\section{Entrapment efficiency}

As observed in Table 2, varying the level of PVA did not affect the entrapment efficiency considerably. At the highest concentration of PVA $(10 \% \mathrm{w} / \mathrm{v})$, slight enhancement in entrapment was facilitated. On the other hand, for a given level of PVA, increasing the concentration of EC the entrapment efficiency decreased. Formulation F6 showed least entrapment efficiency (53.75 \pm 1.29) while highest $(73.00 \pm 1.62)$ was displayed by F7.

\section{In vitro drug release}

The results of the in vitro release experiment (Table 2) reported a decrease in the drug release with increasing amount of PVA $(88.15 \%$ to $66.75 \%$ for F1-F9). Consequently, highest CDR $(88.15 \%)$ was observed for the formulation Flat lowest level of both EC and PVA, while the lowest CDR (66.75\%) at highest level of both ethyl cellulose and PVA was found for F9 (Fig. $3)$. 
Table 2 Evaluation parameters of loratadine microsponges

\begin{tabular}{cccccc} 
Code & $\begin{array}{c}\text { Yield } \\
(\%)\end{array}$ & $\begin{array}{c}\text { Particle size } \\
(\mu \mathrm{m})\end{array}$ & $\begin{array}{c}\text { Entrapment } \\
\text { efficiency }(\%)\end{array}$ & $\% \mathrm{CDR}$ 8h & $\begin{array}{c}\text { Desirability } \\
\text { Factor }\end{array}$ \\
\hline F1 & 42.33 & $54 \pm 2.37$ & $65.98 \pm 2.21$ & $88.15 \pm 1.59$ & 0.872 \\
F2 & 59.33 & $70 \pm 1.81$ & $60.77 \pm 1.72$ & $80.93 \pm 0.12$ & 0.570 \\
\hline F3 & 74.33 & $78 \pm 1.65$ & $58.61 \pm 2.54$ & $73.84 \pm 0.69$ & 0.398 \\
\hline F4 & 50.88 & $66 \pm 1.83$ & $65.08 \pm 0.92$ & $85.13 \pm 1.19$ & 0.732 \\
\hline F5 & 62.00 & $68 \pm 2.06$ & $56.09 \pm 3.14$ & $81.64 \pm 2.16$ & 0.361 \\
\hline F6 & 90.23 & $74 \pm 1.60$ & $53.75 \pm 1.29$ & $70.48 \pm 1.85$ & 0.064 \\
\hline F7 & 50.22 & $68 \pm 1.74$ & $73.00 \pm 1.62$ & $76.11 \pm 1.24$ & 0.752 \\
\hline F8 & 56.44 & $72 \pm 1.60$ & $63.11 \pm 2.77$ & $72.54 \pm 2.19$ & 0.416 \\
\hline F9 & 80.66 & $110 \pm 1.77$ & $59.42 \pm 3.38$ & $66.75 \pm 2.43$ & 0.010
\end{tabular}

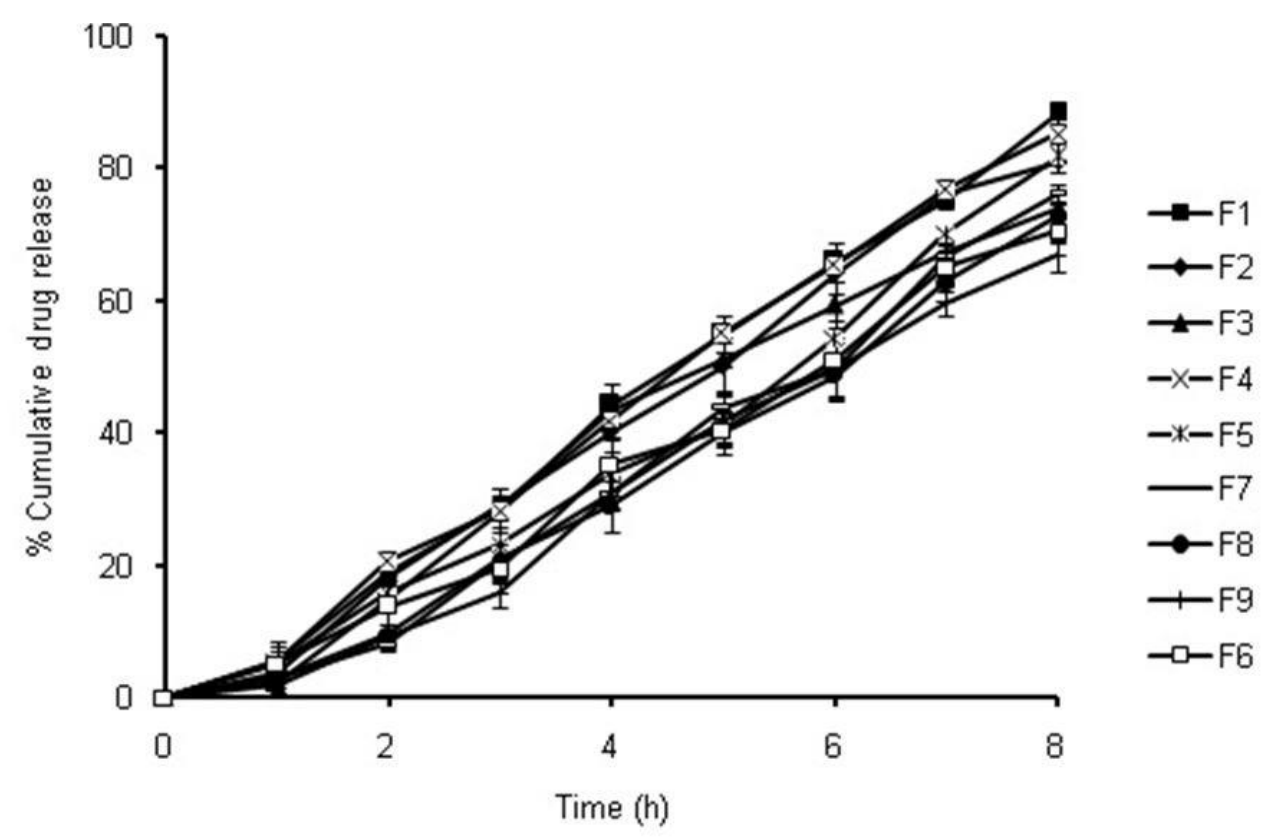

Figure 3 In vitro release profiles of F1-F9 in phosphate buffer, $\mathrm{pH} 4.5$ using Rosette Rice apparatus. 
Statistical analysis and selection of optimized formulation

The statistical analysis of $3^{2}$ full factorial design formulations was performed by Design expert software version 9.0.5.1 (StatEase, Inc., Minneapolis, USA). Second order polynomial equations were generated and one way ANOVA was performed to identify the insignificant factors. The reduced polynomial equations of three dependent variables can be given as follows:

Particle size $(\mu \mathrm{m})=73.39+12.24 \mathrm{X}_{1}$

Entrapment efficiency $(\%)=56.54-5.38 \mathrm{X}_{1}$ $+1.70 \mathrm{X}_{2}-1.55 \mathrm{X}_{1} \mathrm{X}_{2}+2.65 \mathrm{X}_{1}^{2}+5.17 \mathrm{X}_{2}^{2}$

$\mathrm{CDR}_{8 \mathrm{~h}}(\%)=77.29-6.39 \mathrm{X}_{1}-4.59 \mathrm{X}_{2}$

The experimental design was validated by preparing an extra design check point formulation F10. The polynomial equations (2-4) were utilized for calculating the predicted values of particle size, entrapment efficiency and $\mathrm{CDR}_{8 \mathrm{~h}}$ (Table 3). Low values of percentage error between predicted and experimental values affirmed the prognostic ability of the design. To visualize the effect of variables on the responses, response surface plots were generated (Fig. 4). Formulation $\mathrm{F} 1$ yielding the highest desirability factor of 0.872 that exhibited least particle size of $54 \pm 2.37 \mu \mathrm{m}$, entrapment efficiency of $65.98 \pm 2.21 \%$ and $\mathrm{CDR}_{8 \mathrm{~h}}$ of $88.15 \pm 1.59 \%$ was selected. The results of dynamic laser scattering revealed bimodal distribution with a specific surface area of 437.35 $\mathrm{cm}^{2} / \mathrm{mL}$.

\section{Bioadhesive microsponges}

The bioadhesive microsponges (BF1) with an average particle size of $84 \pm 2.29$ $\mu \mathrm{m}$ were fabricated. The entrapment efficiency of $55.19 \pm 1.36 \%$ for BF1that was lesser than F1 $(65.98 \pm 2.21)$. The in vitro drug release from BF1 was $81.65 \pm$ $3.37 \%$ is less than $\mathrm{F} 1$ which was $88.15 \pm$ $1.59 \%$ in $8 \mathrm{~h}$ with a similarity factor $(f 2)$ of 83 and dissimilarity factor $(f 1)$ of 15 .

\section{Dynamic in vitro bioadhesion}

At the start of test, none of the microsponges (F1) showed movement when plate A was tilted at 30, 45 and 60 angles. However, at $75^{\circ}$ and $90^{\circ}$ tilt, one and three microsponges respectively, rolled down the plate. In case of BF1 formulation not a single microsponge slide or rolled down even at extreme angle of $90^{\circ}$.

Table 3 Comparison of predicted and experimental data of extra design check point formulation

\begin{tabular}{ccccc}
\hline Code & Response & $\begin{array}{c}\text { Predicted } \\
\text { value }\end{array}$ & $\begin{array}{c}\text { Experimental } \\
\text { value }\end{array}$ & $\begin{array}{c}\text { Percentage } \\
\text { Error }\end{array}$ \\
\hline F10 & Particle size $(\mu \mathrm{m})$ & 79.51 & 86.00 & 8.16 \\
& EE $(\%)$ & 56.26 & 58.79 & 4.49 \\
& $\% \mathrm{CDR}_{8 \mathrm{~h}}$ & 71.80 & 73.88 & 2.89 \\
\hline
\end{tabular}




\section{Ex-vivo permeation}

The cumulative drug permeation (CDP) from $\mathrm{F} 1$ and $\mathrm{BF} 1$ through gastric mucin was found to be $49.12 \%$ and $52.87 \%$ respectively in $8 \mathrm{~h}$ and followed zero order kinetics with $r^{2}$ value of 0.9809 of Fland 0.9885 of BF1 (Fig. 5).

\section{Scanning Electron Microscopy}

Loratadine was clearly seen as needle shaped crystals (Fig. 6a) that was almost lost in microsponges.

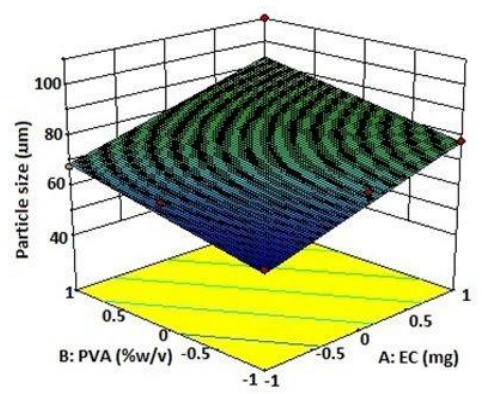

(a)

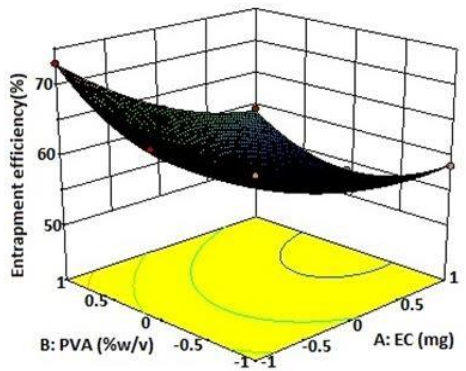

(b)

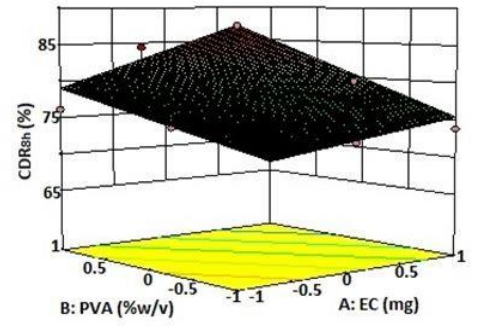

(c)

Figure 4 3D surface plots for analysis of response parameters

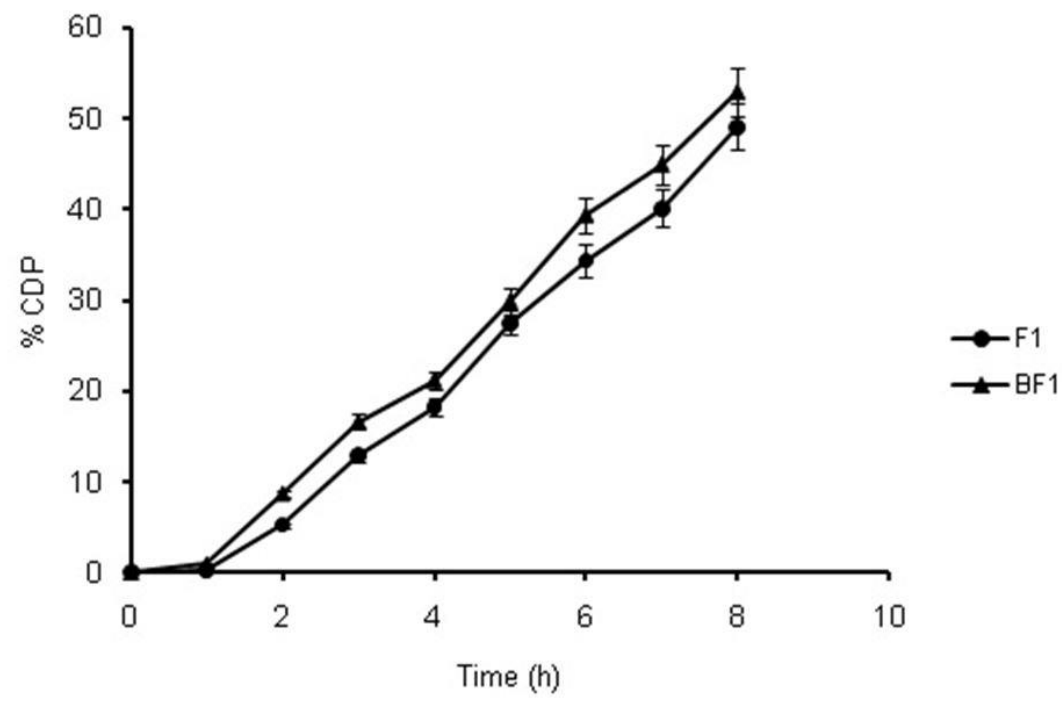

Figure 5 Ex- vivo permeation profiles of $\mathrm{F} 1$ and $\mathrm{BF} 1$ across gastric mucin 


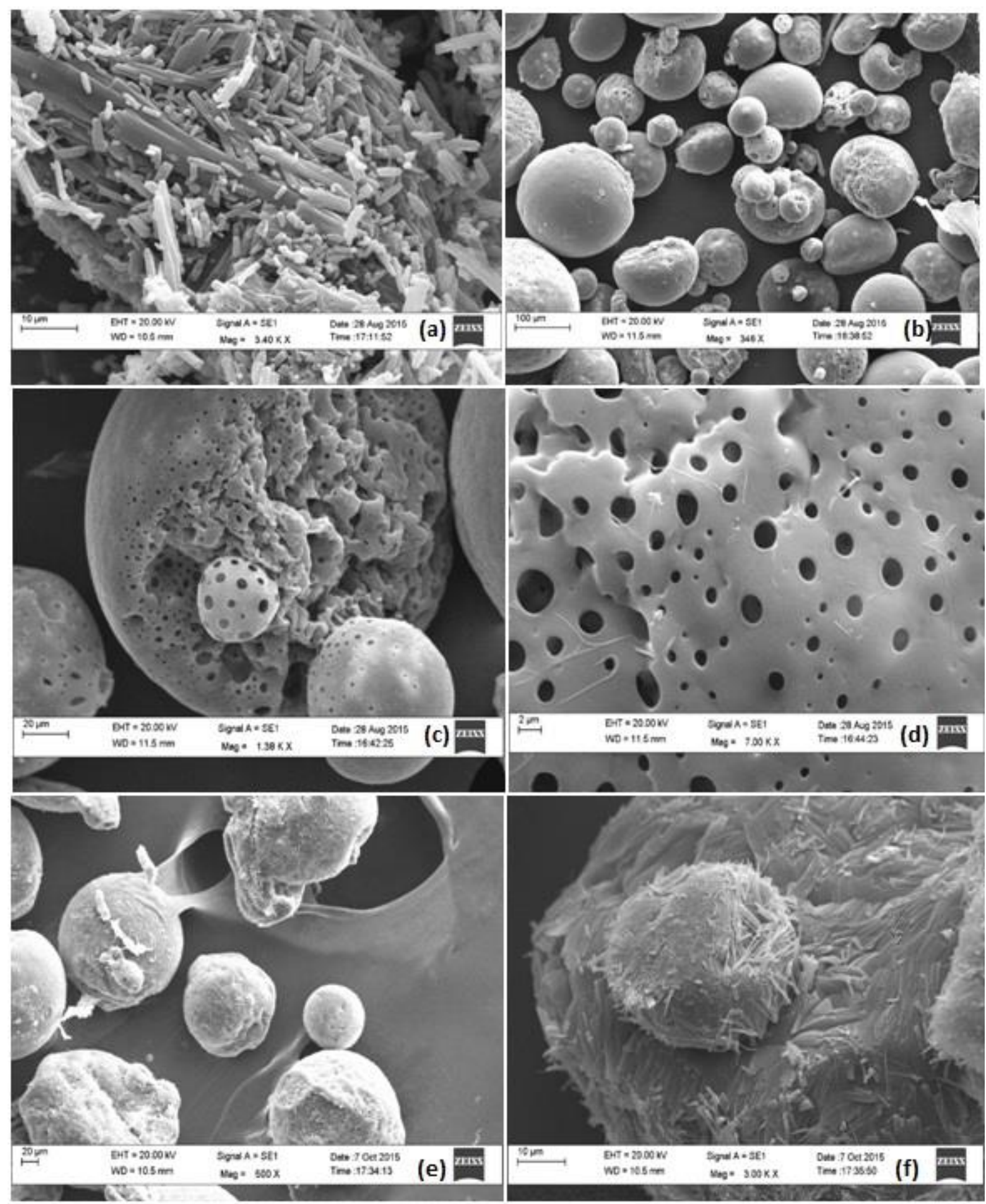

Figure 6 Scanning electron micrographs (a) loratadine crystal (b) optimized microsponges (F1), (c) inner surface view of fractured microsponges, (d) porous surface view of F1 (e) bioadhesive microsponges (BF1), (f) surface view of BF1 microsponge 
The magnified view suggested fluidic Ac deposits on the microsponge surface with numerous needle shaped crystals (probably of loratadine) embedded in it (Fig. 6f).

\section{Interaction Status}

The FTIR spectrum (Fig. 7) of loratadine showed major peaks found at $1695.5 \mathrm{~cm}^{-1}$ ( $\mathrm{C}=\mathrm{O}$ stretch), $\mathrm{C}=\mathrm{C}, \mathrm{C}=\mathrm{N}$ stretch (aromatic) at $1559.51 \mathrm{~cm}^{-1}, \mathrm{~N}=\mathrm{O}$ stretch at 1437.03 $\mathrm{cm}^{-1}, \mathrm{C}-\mathrm{N}$ stretch at $1385.91 \mathrm{~cm}^{-1}, \mathrm{C}-\mathrm{O}$ stretch at $1228.71 \mathrm{~cm}^{-}{ }^{1}$ and $\mathrm{C}-\mathrm{Cl}$ stretch at $997.24 \mathrm{~cm}^{-1}$. These values were corelatable with the values reported in literature (6).

\section{Discussion}

In vitro adsorption study was performed to select the optimum stirring time for the preparation of microsponges so as to achieve maximum drug entrapment. The adsorption of loratadine on EC can be explained as the phenomenon wherein oxygen atom of ester group present in loratadine interacts with hydrogen atom of hydroxyl group present in EC due to the formation of intermolecular hydrogen bonding (12). The morphology of cellulose has a profound effect on its reactivity, the hydroxyl groups located in the amorphous regions are highly accessible and react readily (13). Thus in vitro adsorption study helped in selection of a stirring time of $4 \mathrm{~h}$.

The equilibrium solubility study was performed to observe the impact of excipients on the solubility of loratadine. The increase in solubility of loratadine by 14.24 fold using Ac may be explained by increased wettability of loratadine particles and micellar solubilisation of the drug. Indeed, Ac being a surfactant causes a decrease in the interfacial tension between the drug and the dissolving medium (14). Thus Ac could enhance drug loading in the microsponges. The microsponges were fabricated with EC which is biologically inert, non-irritating, non-mutagenic, non-allergenic, non-toxic and non-biodegradable polymer (15). The modified emulsion solvent diffusion method was used for the preparation of microsponges because of its simplicity and reproducibility, Moreover, it has the advantage of avoiding solvent toxicity (16). Principally, the microsponge formation by emulsion solvent diffusion method involves rapid diffusion of dichloromethane (good solvent for the polymer and drug) into the aqueous medium that reduces the solubility of the polymer in the droplets, since the polymer was insoluble in water. The instant mixing of dichloromethane and water at the interface of the droplets induces precipitation of the polymer, thus forming a shell enclosing the dichloromethane and the dissolved drug. The finely dispersed droplets of the polymer solution of the drug are then solidified in the aqueous phase via diffusion of the solvent (17). Based on the said principle, nine formulations of loratadine microsponges were fabricated using $3^{2}$ factorial design. As the concentration of polyvinyl alcohol was increased from 5 to $7.5 \% \mathrm{w} / \mathrm{v}$, the yield increased. The reason attributable was that the abridged dichloromethane diffusion rate from concentrated solutions to aqueous phase at higher EC concentrations provided additional time for formation of droplet, thereby improving yield (18). However, further increase in the amount of PVA from 7.5 to $10 \% \mathrm{w} / \mathrm{v}$ resulted in decreased yield. It 


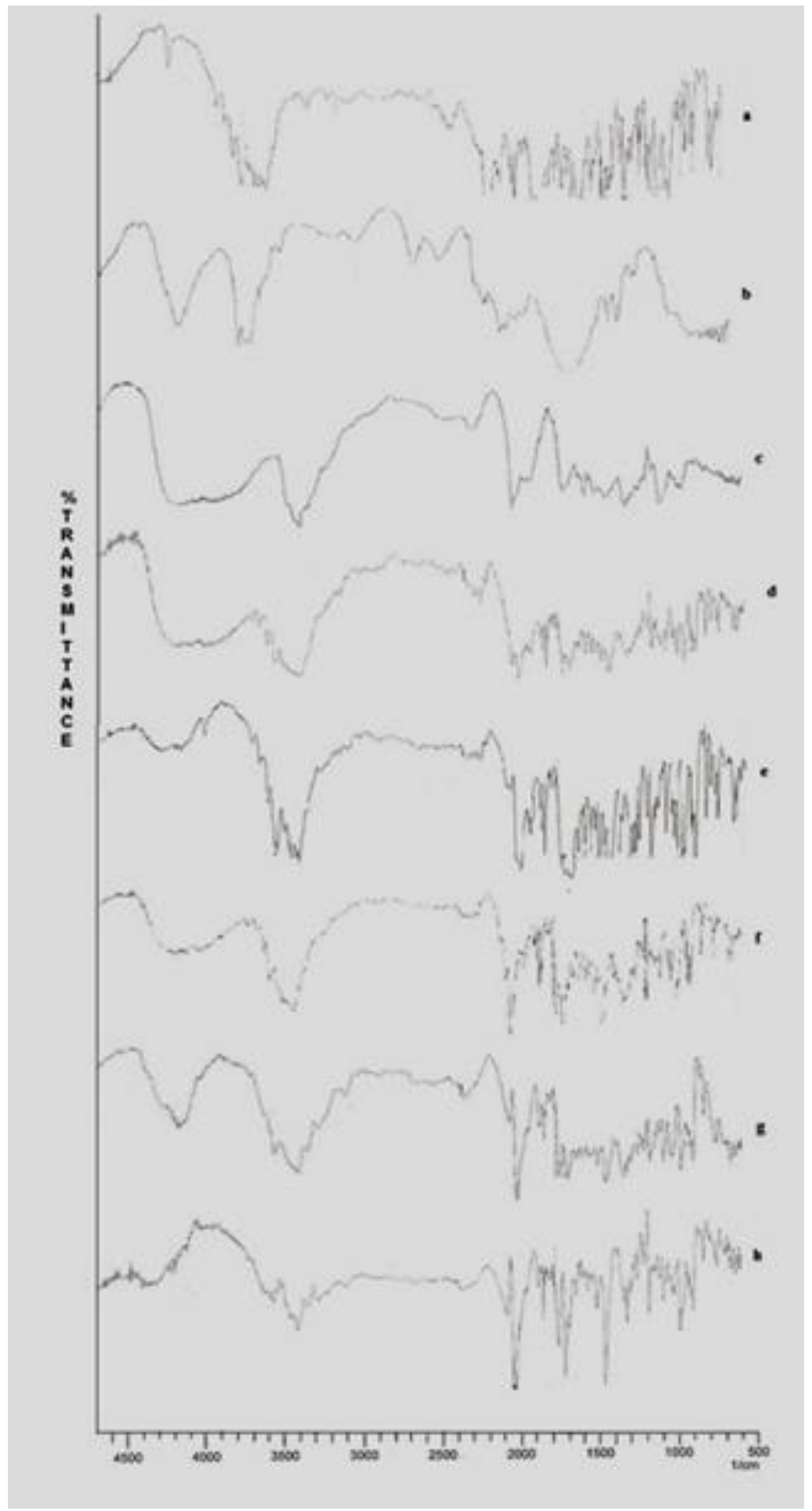

Figure 7 FTIR spectra of (a) loratadine, (b) EC, (c) Ac, (d) loratadine +Ac, (e) loratadine $+\mathrm{EC}$, (f) loratadine $+\mathrm{Ac}+\mathrm{EC}$, (g) optimized formulation (F1), (h) bioadhesive formulation (BF1) 
was due to fact that the emulsifier (non-ionic in nature) possibly presented some hydrophobic regions that dissolved some of the loratadine and EC. The molecules might have associated away from the oil-water interface at higher concentrations resulting in alternative hydrophobic region which dissolved some portion of loratadine resulting in a reduction in yield of microsponges (19). The reason could be attributed to decreased evaporation rate of solvent from the concentrated solution into the external phase (20). The effect of varying the levels of EC and PVA on the response parameters was assessed.

The effect of varying the levels of PVA on particle size could be clearly seen. An increase in PVA concentration to $10 \% \mathrm{w} / \mathrm{v}$ increased the viscosity of the $\mathrm{o} / \mathrm{w}$ emulsion, resulting in an increased difficulty to break up the emulsion into smaller droplets (21). This resulted in larger emulsion droplet formation and finally in larger microsponge size. Furthermore, shearing efficiency during stirring also diminishes at higher viscosities, thus resulting in the formation of larger droplets and hence bigger particles (22). For a given level of PVA, the particle size was increased on increasing the concentration of EC. This might be due to the fact that EC was available in greater amount thereby increasing the wall thickness, which consequently led to larger microsponges. This is likely due to the increase in the viscosity of the medium at higher EC concentrations resulting in an enhanced interfacial tension. At a fixed low stirring shear force, small emulsion droplets are difficult to form (23).
The level of PVA did not affect the entrapment efficiency considerably. At the highest concentration of PVA (10 \%w/v), slight enhancement in entrapment was facilitated. On the other hand, for a given level of PVA, increasing the concentration of ethyl cellulose the entrapment efficiency decreased. As explained by Chella et al. (24), an increase the concentration of ethyl cellulose levels leads to formation of larger polymer/solvent droplets. The larger particles take much time for hardening, allowing sufficient time for drug diffusion out of the particles, which tends to decrease the entrapment efficiency. The volume of organic solvent (DCM) used, may also impact the entrapment efficiency. Less volume $(5 \mathrm{~mL})$ of organic solvent used (in comparison to report by Nokhodchi et al. (25) that states use of $20 \mathrm{~mL}$ ) is expected to decrease rate of evaporation and hence lower solvent front kinetic energy. This decreases the rate of diffusion of the solvent from the inner to the outer phase so increasing the chance for entrapping the drug inside the EC (26).

For a given level of PVA, the CDR (\%) was observed to decline with respect to rise in EC amount from $100 \mathrm{mg}$ to $400 \mathrm{mg}$. The reason attributable is, as the amount of EC increased; an increase in the EC solution viscosity produced microsponges with reduced porosity due to the thickening of the ethyl cellulose wall. The thick polymeric barrier slows the entry of surrounding dissolution medium in to the microsponges and hence less quantity of drug leaches out from the polymer matrices of the microsponges exhibiting extended release (18). It is understood that higher EC 
concentration results in a longer diffusional path length, so the drug release was extended. The release kinetics best fitted a zero-order kinetic model ((highest $r^{2}$ values) except for F3 that best fitted Hixson Crowell model. No concrete explanation could be found and was concluded as a stray result. Zero order drug release from microsponges has been reported by other researchers also for prednisolone microsponges (27), miconazole nitrate microsponges (28), aceclofenac microsponges (29) and meloxicam microsponges (30).

An optimization technique using desirability criteria was employed to select the optimized formulation. Optimization by experimental design leads to the evolution of a statistically valid model to understand the relationship between independent and dependent variables. For the selection of optimized formulation, Design Expert software was utilized. Thus, optimized formulation F1 was selected on the basis of minimum particle size, high entrapment efficiency, maximum in vitro cumulative drug release in $8 \mathrm{~h}$ and with good desirability factor. The particle size distribution of $\mathrm{F} 1$ was bimodal with a specific surface area of 437.35 $\mathrm{cm}^{2} / \mathrm{mL}$. The distribution was left skewed distribution and was platykurtic with a relatively more peaked distribution. Skewness and kurtosis are significant parameters to measure the degree of departure from normal frequency (31).

The optimized formulation was modified by adding bioadhesive raw material to prepare bioadhesive microsponges (BF1). Owing to the intrinsic bioadhesive property, acconon MC 8-2 EP/NF (Ac) was selected for preparing microsponges. The process variables of optimized formulation (F1), with slight modification were used for fabrication of microsponges using Ac MC 82. The amount of EC was reduced to $80 \mathrm{mg}$ instead of $100 \mathrm{mg}$ because at latter concentration the microsponges got aggregated. The entrapment efficiency of BF1was lower than F1. Lower entrapment in case of BF1 can be attributed to fewer adsorption sites available to entrap drug as lower amount of EC was used in fabrication of BF1. Similarly, the in vitro drug release from $\mathrm{BF} 1$ was less than $\mathrm{F} 1$ with a similarity factor $(f 2)$ of 83 . A similarity factor of 83 suggests similar release profiles of $\mathrm{F} 1$ and BF1 despite the fact that the drug entrapment efficiency of BF1 was lower than F1. With modulation of formulation and process variables the entrapment efficiency could be improved and a higher/ complete release of drug could be achieved.

The dynamic in vitro bioadhesion study was performed to assess the ex vivo bioadhesivity. BF1 showed higher ex vivo bioadhesivity than F1. Stronger bioadhesivity of BF1 is accountable to Ac that contains free macrogols. The macrogols are adhesive in nature and have been reported as bioadhesive polymer (32). The improved bioadhesivity can also be attributed to low amount of EC used in BF1 that offered less hindrance to bioadhesion. However, insignificant difference in ex vivo permeation was found between them.

Morphology and surface topography of prepared microsponges were visualized by SEM analysis. F1 was spherical shaped microsponges with porous polymeric matrix and the outer surface revealed numerous pores over it. On the other hand BF1 was 
constituted of spheroidal microsponges with fluidic Ac deposits on the microsponge surface with numerous needle shaped crystals (probably of loratadine) embedded in it. The concentration of these crystals on the surface may be explained on the basis of solublizing action of Ac that favored partitioning of the drug in Ac. Later on evaporation of the coating solvent led to needle shaped deposits of loratadine on the surface. These deposits are expected to enhance drug release.

The FTIR spectra of loratadine in its physical mixture with excipients retained the major peaks and no shift of peak (s) or disappearance / modification of the principle peaks indicated any interaction between the drug and excipients used for fabrication of microsponges.

\section{References}

1. Goodman and Gillman, The Pharmacological basis of Therapeutics. McGraw Hill, New York, 1996, $11^{\text {th }}$ edition, 638.

2. Singh N, Kumar M, Pathak K. Optimization of diltiazem hydrochloride loaded mucoadhesive floating microspheres as calcium carbonate as floatation aid. Ind J Pharm Ed Res 2014;48:60-74.

3. Begum MY, Avanthi J, Shwetha A, Madhuri T, Sudhakar M, Naveen D. Formulation and evaluation of sustained release floating tablets of loratadine. Int J Pharm Sci Res 2014;5:4375-85.

4. Kumar AD, Rani JM, Sudhakarbabu AMS, Rao VP. Formulation, optimization and evaluation of loratadine gastro retentive tablets. Int J Biol Pharm Res 2013;4:1190-95.

5. Vachhani SR, Patel JJ, Patel D, Prajapati ST, Patel $\mathrm{CN}$. Formulation and in-vitro evaluation of floating capsules of loratadine. J Chem Pharm Res 2010;2:57-64.

6. Nayak KP, Upadhyay P, Deshpande J, Valera JDAR, Chauhan NP. Gastroretentive drug delivery systems and recent approaches: a review. J Pharm Res Opin 2012;2:1-8.

\section{Conclusion}

Bioadhesive floating microsponges of loratadine were successfully developed. Assessment of Acconon MC 8-2 EP/NF as a bioadhesive polymeric surfactant for preparation of microsponges emerged as a successful approach. The study clearly demonstrates a synergic drug delivery system that could increase drug retention time in the gastric chamber.

\section{Conflict of Interest}

The authors declared no potential conflict of interest with respect to the authorship, and/or publication of this study.

7. Misra SK, Pathak K. Formulation and evaluation of oil entrapped gastroretentive floating gel beads of loratadine. Acta Pharm 2008;58:187-97.

8. Arya P, Pathak K. Assessing the viability of microsponges as gastro retentive drug delivery system of curcumin: Optimization and pharmacokinetics. Int J Pharm 2014;460:1-12.

9. Zhao S, Lv Y, Zhang JB, Wang B, Lv GJ, Ma $\mathrm{XB}$. Gastroretentive drug delivery systems for the treatment of Helicobacter pylori. World J Gastroenterol 2014;20:9321-9.

10. Nokhodchi A, Jelvehgari M, Siahi MR, Mozafari MR. Factors affecting the morphology of benzoyl peroxide microsponges. J Microencapsulation 2007;38:834-40.

11. Rajput P, Singh D, Pathak K. Bifunctional capsular dosage form: Novel fanicular cylindrical gastroretentive system of clarithromycin and immediate release granules of ranitidine $\mathrm{HCl}$ for simultaneous delivery. Int J Pharm 2014;461:31021.

12. Lommerse JPM, Price SL, Taylor R. Hydrogen bonding of carbonyl, ether, and ester oxygen 
atoms with alkanol hydroxyl groups. J Comput Chem 1997;18:757-74.

13. Kamel S, Ali N, Jahangir K, Shah SM, El-Gendy AA. Pharmaceutical significance of cellulose: A review. Express Polym Lett 2008;2:758-78.

14. Singh SN, Patil UK. Solubility and pre formulation studies of non micronized piroxicam SEDDS. J Pharm Res Clin Prac 2014;4:42-52.

15. Parikh BN, Gothi GD, Patel TD, Chavda HV, Patel CN. Microsponge as novel topical drug delivery system. J Global Pharm Tech 2010;2:1729.

16. Jain N, Sharma PK, Banik A. Recent advances on microsponge delivery system. Int J Pharm Sci Rev Res 2011;8:13-23.

17. Saboji JK, Manvi FB, Gada AP, Patel BD. Formulation and evaluation of ketoconazole microsponge gel by quasi emulsion solvent diffusion. J Cell Tissue Res 2011;11:2691-6.

18. Moin A, Deb TK, Osmani RAM, Bhosale R R, Hani U. Fabrication, characterization, and evaluation of microsponge delivery system for facilitated fungal therapy. J Basic Clin Pharm 2016;7:39-48.

19. Jelvehgari M., Siahi-Shadbad MR, Azarmi S, Martin GP, Ali N. The microsponge delivery system of benzoyl peroxide: Preparation, characterization and release studies. Int J Pharm 2006;308:124-32.

20. Khonsari F, Zakeri-Milani $\mathrm{P}$, Jelvehgari $\mathrm{M}$. Formulation and evaluation of in vitro characterization of gastic-mucoadhesive microparticles/discs containing metformin hydrochloride. Iran J Pharm Res 2014; 1: 67-80.

21. Maia JL, Santana MHA, Ré MI. The effect of some processing conditions on the characteristics of biodegradable microspheres obtained by an emulsion solvent evaporation process. Brazilian $\mathrm{J}$ Chem Engg. 2004;2:11-2.

22. Garud N, Garud A. Preparation and in-vitro evaluation of metformin microspheres using nonaqueous solvent evaporation technique. Trop $\mathrm{J}$ Pharm Res 2012;11:577-83.

23. Prasertmanakit S, Praphairaksit N, Chiangthong $\mathrm{W}$, Muangsin N. Ethyl cellulose microcapsules for protecting and controlled release of folic acid. AAPS Pharm Sci Tech 2009;10:1104-12.
24. Chella N, Yadav KK, Vempati R. Preparation and evaluation of ethyl cellulose microspheres containing diclofenac sodium by novel w/o/o emulsion method. J Pharm Sci Res 2010;2:884-8.

25. Nokhodchi A, Jelveghari M, Siahi M, Dastmalchi $\mathrm{S}$. The effect of formulation type on the release of benzoyl peroxide from microsponges. Iran $\mathrm{J}$ Pharm Sci 2005;1:131-42.

26. Abdelmalak NS, Menshawe S. A new topical fluconazole microsponge loaded hydrogel: Preparation and characterization. Int J Pharmacy Pharm Sci 2012;4:460-8.

27. Singh RPS, Prajapati SK. Formulation and evaluation of prednisolone loaded microsponges for colon drug delivery: in vitro and pharmacokinetic study. Int J Pharm Sci Res 2014;5:1994-2005.

28. Savaliya B, Kavar R, Talaviya N. Miconazole nitrate microsponge for topical drug delivery system, Lambert Academic Publishing 2015.

29. Singh RP, Singh S. Optimization and evaluation of aceclofenac loaded microsponges prepared by quasi-emulsion diffusion technique. Metabolomics 2013;2:129-32.

30. Srivastava R, Kumar D, Pathak K. Colonic luminal surface retention of meloxicam microsponges delivered by erosion based colon targeted matrix tablet. Int J Pharm 2012;472:15362.

31. Dabas S, Shakya P, Sharma V, Pathak K. Effect of milling on correlation between interquartile coefficient of skewness and coefficient of kurtosis in pharmaceutical powders. Ind J Pharm Ed Res 2009;43:32-9.

32. Muttukumaran $M$, Dhachinamurthi D, Chandrashekhar KB, Sriram N. Polymers in mucoadhesive drug delivery system: a brief note. Int J Pharm Ind Res 2011;1:122-7. 